\title{
Comité Científico de la Sociedad de Cirujanos de Chile. Enmendando el rumbo
}

\author{
Scientific Committee of the Society of Surgeons of Chile. Amending the way
}

\author{
Dr. Mario Uribe M.
}

Estos dos últimos años nuestra Sociedad no tuvo Comité Científico (C.C.). Los integrantes anteriores cumplieron su período y no fueron nombrados oficialmente sus reemplazantes. Lo anterior tuvo como resultado varios problemas, que el actual Directorio está intentando remediar. No hubo entrega de premios societarios, pues no hubo quiénes los adjudicaran, no existió una instancia para la aceptación calificada de trabajos científicos para el congreso, entre muchas otras falencias. En definitiva faltó esta entidad encargada de velar por la excelencia académica de las actividades societarias, de programarlas y proyectarlas.

Una Sociedad Científica, sin Comité Científico es una Sociedad sin rumbo. Afortunadamente esto corresponde al pasado.

El Dr. Francisco López, en su Editorial de la SCCH del año 2012, hizo una fuerte crítica al rol secundario que, forzadamente había tenido el C.C., planteando múltiples actividades a realizar para corregirlos, en forma seria y responsable. Actualmente se ha reiniciado el proceso que iniciáramos, cuando fui Presidente de la Sociedad, junto al entonces Presidente del C.C. Dr. López en aras de conseguir un C.C. de excelencia, representativo, independiente y pluralista

El Directorio dirigido por el Dr. Nicolás Jarufe, me escogió como el nuevo Presidente del Comité Científico, encomendándome la elaboración de un Reglamento, el que fue propuesto y aceptado para su implementación. Destaco algunos aspectos relevantes del mismo.

El objetivo del Comité Científico es promover la actividad científica y académica de la Sociedad de Cirujanos de Chile ( $\mathrm{SCCH})$ a través de reuniones, cursos, congresos, material impreso y los medios audiovisuales que se consideren necesarios para informar, educar, actualizar, divulgar y promover la información científica en el ámbito de la cirugía, también deberá colaborar con el Editor de la Revista
Chilena de Cirugía y su Comité Editorial para la selección de contenidos a objeto de mejorar la calidad e índice de impacto de la Revista.

Las funciones del Comité Científico en relación al congreso anual han sido definidas en dicho reglamento, dentro de los cuales destacamos: Revisar y publicar la Pauta de Evaluación de trabajos para el congreso, implementar un sistema de doble evaluación de cada trabajo, fijar un puntaje mínimo de aceptación de los mismos, dirimir diferencias en puntaje, acoger apelaciones de los autores, ordenar por puntajes los trabajos aceptados, elaborar reglamentos para las áreas de su incumbencia, entre otras.

El Presidente del Comité Científico, junto con el Presidente de la $\mathrm{SCCH}$, deberá reunirse, a lo menos una vez al año, con los Presidentes de los Departamentos y de las Sociedades asociadas para dar a conocer el Programa Anual y recibir sugerencias. Asimismo, deberá elaborar un Plan Anual de trabajo, realizar dos cursos de Evaluadores Científicos al año y asegurar un mínimo de Evaluadores por Departamento y estar disponibles para cualquier otra labor que sea requerida por el Directorio y/o el Comité Organizador del Congreso.

Este reglamento también incluye un mecanismo de elección del Presidente del C.C. y sus otros cuatro integrantes, de reelección y eventual eliminación de sus miembros y un período máximo de permanencia en el cargo.

Un punto siempre sensible para los socios es la evaluación de los trabajos y vídeos enviados para ser presentado en el congreso. El 2014, a nuestra solicitud, el Dr. Carlos Manterola, confeccionó una nueva pauta de evaluación y, lo más importante, desde esa fecha, se han realizados dos cursos anuales de "Evaluadores de trabajos científicos", adquiriendo experiencia en la aplicación de la misma. La plataforma computacional impide que un revisor evalúe trabajos de su mismo centro, la aplicación de la pauta se hace con desconocimiento absoluto de parte
Presidente Comité Científico

Correspondencia a: Mario Uribe M. muribemd@hotmail.com 
del evaluador tanto del autor del trabajo, como del centro a que pertenece. Esta pauta, moderna y exigente, está en constante revisión y, estamos ciertos, nos permitirá en un futuro cercano, mejorar en forma significativa la calidad de nuestros congresos y posicionarnos entre las sociedades científicas líderes en este aspecto.

Nuestro objetivo es, a la brevedad posible, contar con una doble evaluación de todos los trabajos. Esta conducta será especialmente importante para aquellos trabajos que hayan quedado a escasos puntos por debajo del porcentaje de aprobación. Vamos a contar con un período de apelación abierto a los autores cuyos trabajos hayan sido rechazados, siendo analizados esta vez por los miembros del C.C., cuya decisión será inapelable. Nos hemos dado cuenta, que deben existir pautas diferentes de evaluación, las que hemos creado recientemente; una para trabajos científicos, otra para casos clínicos y una tercera para vídeos, evitando los sesgos propios de aplicar una pauta inadecuada a ponencias esencialmente diferentes, como ha ocurrido previamente.

En relación a la asignación de premios; se mantiene el camino iniciado el año 2014 de entregar los siguientes premios "Maestro de la Cirugía Chilena" al mejor trabajo clínico y "Presidente de la Sociedad de Cirujanos" al mejor trabajo experimental, publicados en la Revista de la $\mathrm{SCCH}$ el año previo al Congreso.

"Premio Visita Académica Sociedad de Cirujanos de Chile - Nombre del auspiciador". Este premio reemplaza a varios otros entregados el año 2014 que permitían estadas de capacitación financiadas, tanto en el país como en el extranjero y que, desgraciadamente, fueron discontinuados. Este premio es otorgado por postulación y la visita debe ser parte de un proyecto institucional del centro que avala su postulación.

"Mejor Trabajo del Congreso" del año en curso.

"Mejor Póster del Congreso" del año en curso.

El Premio Presidente SCCH y Maestro SCCH, llevarán el nombre de aquellos cirujanos que fueron distinguidos en esos cargos, en forma correlativa desde la fundación de nuestra Sociedad

Otro premios que deseamos implementar es un reconocimiento a miembros de la Sociedad por artículos publicados en revistas internacionales, el que sería por postulación y se dirimiría, por el índice de impacto de la revista respectiva.

Hemos terminado con el requisito de postulación a premios de que el primer autor de un trabajo deba ser MSCCH, restringiéndose en que debe existir, a lo menos, un autor que cumple este requisito. De esta forma se facilita la renovación de los autores y se fomenta la actividad científica.

El Comité Científico en conjunto con los Directores de Departamento fijará el temario de las reuniones científicas y elaborará un formato general de las reuniones de la Sociedad, cooperando en la capacitación de sus miembros a través de múltiples actividades.

Entendemos que el C.C. debe estar al servicio de la Sociedad y sus miembros y supeditado a las decisiones del Directorio, es por ello que realizamos el mayor esfuerzo para responder a sus requerimientos, realizando reuniones periódicas de planificación y evaluación, elaborando un acta de nuestras reuniones., las que son enviadas el Directorio para su conocimiento y aprobación. Pero por otro lado, debe tener la autonomía suficiente para que, en el ámbito de su incumbencia, pueda tomar decisiones y proyectarse en el tiempo más allá de los cambios directivos cotidianos. Es por ello que el reglamento del C.C. debe ser perfeccionado durante este año y presentado, para su aprobación, en la próxima asamblea de socios, legalizándolo de esta forma y haciendo que su contenido sea respetado en el futuro y no dependa sólo de la voluntad de las directivas.

La selección del actual Comité Científico ha sido realizada con mucho esmero, conciliando que haya médicos de regiones y de Santiago, todos ligados a centros docentes universitarios de reconocido prestigio, y que estén representadas múltiples especialidades, entre ellas Digestivo, Vascular, Tórax, Mama y Hepatobiliopancreático, lo que le confiere pluralismo y diversidad favoreciendo un nuevo enfoque que permita reiniciar su reestructuración.

Tenemos el convencimiento que toda nuestra actividad, a la que dedicamos nuestros mayores esfuerzos, se verá recompensada al consolidar importantes logros para nuestra Sociedad.

Estamos en el camino correcto para enmendar el rumbo. 